\title{
Produção de gado de corte e de pastagem de aveia em sistema de integração lavoura-pecuária em presença e ausência de trevo e nitrogênio
}

\section{Tangriani Simioni Assmann ${ }^{1}$, Alceu Luiz Assmann², Joice Mari Assmann ${ }^{3}$, André Brugnara Soares ${ }^{1}$, Marcos Antonio de Bortolli ${ }^{4}$}

${ }^{1}$ Curso de Agronomia da Universidade Tecnológica Federal do Paraná (UTFPR), Campus Pato Branco/PR.

2 Instituto Agronômico do Paraná (IAPAR), Pato Branco/PR.

${ }^{3}$ Mestranda do Programa de Pós-Graduação em Agronomia da Universidade Tecnológica Federal do Paraná (UTFPR), Campus Pato Branco/PR. Bolsista CAPES.

${ }^{4}$ Mestrando do Programa de Pós-Graduação em Agronomia da Universidade Tecnológica Federal do Paraná (UTFPR), Campus Pato Branco/PR.

RESUMO - Objetivou-se avaliar a influência da inclusão de leguminosas (trevos) e da aplicação de nitrogênio em pastagem de aveia sobre a produção e composição estrutural da pastagem e a produção animal em sistema de integração lavoura-pecuária. O delineamento experimental foi o de blocos ao acaso com três repetições. Os fatores foram arranjados em parcelas subdivididas, de modo que as parcelas constituíram-se dos períodos de avaliação e as subparcelas, da combinação de trevo e adubação com nitrogênio (200 kg/ha via ureia). O método de pastejo foi o contínuo, com taxa de lotação variável para manter altura da pastagem de $15 \mathrm{~cm}$. Foram utilizados animais jovens de corte, de aproximadamente dez 10 meses de idade, machos não-castrados da raça Purunã, com peso médio inicial de $200 \mathrm{~kg}$. A produção média de massa de forragem foi de 2.378,96; 3.289,49; e 2.749,86 kg/ha para as pastagens controle, com trevo e com nitrogênio, respectivamente, no período de 12 de julho a 8 de outubro de 2006, totalizando 89 dias de pastejo com oferta de forragem média de 14,90 kg de MS/100 kg de peso vivo e ganho médio diário de 1,280 kg/animal/dia. A pastagem suportou ao final do experimento uma capacidade de transporte de 1.528,25; 1.244,32 e 1.156,17 kg/ha de PV (peso vivo) para a adubação nitrogenada, com trevo e controle, respectivamente. A maior produção animal por hectare foi obtida com adubação nitrogenada (541,49 kg PV/ha). A inclusão de trevo-branco em consórcio com aveia no sistema de integração lavoura-pecuária não é suficiente para manter a sustentabilidade de sistemas intensivos de elevada produtividade.

Palavras-chave: adubação nitrogenada, estrutura de pastagem, pastagem consorciada, relação lâmina/colmo

\section{Beef cattle and oat pasture production in a crop-livestock system in presence and absence of clover and nitrogen}

ABSTRACT - The objective of this work was to evaluate the influence of including legumes (clover) and the application of nitrogen on oat forage structural composition and production and the animal production in crop-live stocking integration system. It was used a random block experimental design with three replications. The factors were arranged in split-plots, so the plots were composed of evaluation periods and the split-plots were composed of the combination of clover with nitrogen fertilization(200 $\mathrm{kg}$ of $\mathrm{N} / \mathrm{ha}$ using urea). The pasture method was the contiuous one, with variable stocking rate to keep forage height at $15 \mathrm{~cm}$. It was used Purunã breed non-castrated young beef bulls at 10 months of age, with an initial average weight of $200 \mathrm{~kg}$. The forrage mass avarage production was 2,378.96, 3,289.49, and 2,749.86 kg/ha for the control pastures, with clover and nitrogen, respectively, from July $12^{\text {th }}$ to October $8^{\text {th }} 2006$, totalizing 89 days of grazing with an average forrage supply of $14.90 \mathrm{~kg} D \mathrm{DM} / 100 \mathrm{~kg}$ body weight and daily weight gain of $1.280 \mathrm{~kg} / \mathrm{animal} / \mathrm{day}$. At the end of the experiment, pasture beared a transportation capacity of $1,528.25 ; 1,244.32$ and $1,156.17 \mathrm{~kg}$ of body weight for nitrogen fertilization, with clover and control, respectively. The highest animal/ha production was obtained with nitrogen fertilization $(541.49 \mathrm{~kg} / \mathrm{ha})$. The inclusion of white clover intercropped with oats in system of crop-livestock integration is not enough to maintain the sustainability of intensive systems high productivity.

Key Words: forage structure, leaf/stem ratio, nitrogen fertilization, pasture consortium

Recebido em 20/10/2008 e aprovado em 29/6/2009.

Correspondências devem ser enviadas para: tangriani@utfpr.edu.br 


\section{Introdução}

Os sistemas de integração lavoura-pecuária necessitam muito de nitrogênio tanto para a pastagem como para a cultura de verão (Assmann et al, 2003; Assmann et al. 2004; Assmann et al, 2007). No entanto, estes sistemas devem ser economicamente eficientes, sem impacto ambiental nem incorrer em práticas que afetem sua sustentabilidade. Convém ressaltar que a dada importância do nutriente nitrogênio, quanto às quantidades requeridas pelas plantas, ao seu valor econômico e ao seu potencial poluidor, é essencial o correto manejo desse nutriente. Independente da fonte de nitrogênio (fixaçao biológica, fertilizante químico ou orgânico), o sistema deve estar bem suprido deste e de outros nutrientes.

A introdução de fabáceas em pastagens de poáceas forrageiras permite, além do enriquecimento de nitrogênio na dieta animal e no solo, melhorar a distribuição da produção de forragem, diminuição de custos de produção da lavoura e da pastagem e um sistema com menor contaminação ambiental (Whitehead, 1995).

Lesama \& Moojen (1999), em trabalho realizado durante o inverno no estado do Rio Grande do Sul, compararam pastagens de: aveia-preta + azevém + trevo vesiculoso; aveia-preta + azevém + trevo vesiculoso + $150 \mathrm{~kg} / \mathrm{ha}$ de $\mathrm{N}$; e aveia-preta + azevém + trevo vesiculoso + $300 \mathrm{~kg} / \mathrm{ha}$ e observaram ganho médio diário de 0,928; 1,091 e 0,839 kg/ animal/dia e ganho de peso vivo de 516,720 e $650 \mathrm{~kg} / \mathrm{ha}$ para os respectivos fatores em estudo, com 96 dias de pastejo, demonstrando inclusive que, nem sempre a inclusão de leguminosa na mescla forrageira se contrapõe ao uso da adubação nitrogenada de cobertura.

Em trabalho de integração lavoura-pecuária Assmann et al. (2004), comparando o efeito de doses de nitrogênio (0, 100, 200 e $300 \mathrm{~kg}$ de N/ha) em pastagem de aveia + azevém em combinação de sub-parcelas com presença e ausência de trevo, não encontraram efeito da inclusão de trevobranco nem da adubação nitrogenada sobre o ganho médio diário sendo observado um valor médio de 0,99 kg/animal/ dia. Sobre o ganho de peso vivo por área não houve o efeito da presença da leguminosa, contudo nas parcelas que receberam $300 \mathrm{~kg} / \mathrm{ha}$ de $\mathrm{N}$ observou-se ganho de peso vivo de $656 \mathrm{~kg} / \mathrm{ha}$, enquanto que nas parcelas cultivadas sem adubação nitrogenada o ganho de peso vivo foi de $480 \mathrm{~kg} / \mathrm{ha}$.

O objetivo neste trabalho foi estudar os efeitos da introdução de trevos (fabáceas) e da adubação nitrogenada em pastagem de aveias (gramíneas temperadas) na produção da pastagem e na produção animal, em um sistema integração lavoura-pecuária.

\section{Material e Métodos}

O experimento foi conduzido no período de maio a outubro de 2006, na área experimental do Instituto Agronômico do Paraná (IAPAR), situada na região fisiográfica denominada Terceiro Planalto Paranaense, em altitude média de $730 \mathrm{~m}$, latitude $25^{\circ}$ 07' Sul e longitude $52^{\circ} 41^{\prime}$ Oeste. A área experimental utilizada vem sendo trabalhada há quinze anos no sistema de semeadura direta, sendo que há cinco anos a área vem recebendo o cultivo de pastagens de inverno, e no verão o cultivo de milho e soja no sistema de integração lavoura-pecuária típico do sul do Brasil.

O solo é classificado como latossolo vermelho distrófico (EMBRAPA, 1999), desenvolvido a partir de rochas eruptivas básicas, sendo profundo, bem drenado, com coloração vermelho-escura e textura muito argilosa (>600 g/kg) (Tabela 1$)$. O relevo configura-se como ondulado a suave ondulado. O clima da região é Cfa (subtropical úmido), conforme classificação de Köppen.

O delineamento experimental foi o de blocos ao acaso com três repetições. Os fatores foram arranjados em parcelas subdivididas, de modo que, nas parcelas, foram avaliados os períodos de avaliação e nas subparcelas, a adição de nitrogênio. No manejo da aveia com adubação, o nitrogênio foi aplicado na forma de uréia (200 kg/ha) e no manejo da aveia com trevo, trabalhou-se com a mistura entre aveia e trevo sem aplicação de nitrogênio.

A semeadura foi realizada em sistema plantio direto no dia 26/5/2006 com $60 \mathrm{~kg} /$ ha da mistura de aveias, sendo 50\% de aveia-branca (Avena sativa L.) cultivar IPR 126 e 50\% da aveia-preta (Avena strigosa Schereb) cultivar IAPAR 61. Para compor o tratamento de aveia com trevo, além das sementes de aveia, utilizou-se de trevo-branco (Trifolium

Tabela 1 - Análise química do solo, em três profundidades, anterior à instalação do experimento (maio, 2006)

\begin{tabular}{|c|c|c|c|c|c|c|c|c|c|}
\hline \multirow{2}{*}{$\begin{array}{l}\text { Profundidade } \\
\text { cm }\end{array}$} & \multirow{2}{*}{$\begin{array}{c}\mathrm{pH} \\
\mathrm{CaCl}_{2}\end{array}$} & \multirow{2}{*}{$\begin{array}{c}\text { Matéria orgânica } \\
\text { g/dm }\end{array}$} & $\mathrm{Al}^{+3}$ & $\mathrm{H}+\mathrm{Al}$ & Cálcio & Magnésio & Potasio & \multirow{2}{*}{$\begin{array}{l}\text { Fósforo } \\
\mathrm{mg} / \mathrm{dm}^{3}\end{array}$} & \multirow{2}{*}{$\begin{array}{c}\text { Saturação por bases } \\
\%\end{array}$} \\
\hline & & & \multicolumn{5}{|c|}{$\mathrm{Cmol}_{(\mathrm{c})} / \mathrm{dm}^{3}$} & & \\
\hline $0-5$ & 5,1 & 73,81 & 0,00 & 6,57 & 7,36 & 3,26 & 0,80 & 5,92 & 63,48 \\
\hline $5-10$ & 4,9 & 60,75 & 0,05 & 7,55 & 6,51 & 2,90 & 0,64 & 1,82 & 57,10 \\
\hline $10-20$ & 4,9 & 55,43 & 0,04 & 7,12 & 6,48 & 3,16 & 0,53 & 1,37 & 58,82 \\
\hline
\end{tabular}


repens L.) na quantidade de $4 \mathrm{~kg} / \mathrm{ha}+2 \mathrm{~kg} / \mathrm{ha}$ de trevovermelho (Trifolium pratense L.), semeados a lanço.

A adubação de base foi realizada no momento da semeadura, utilizando $250 \mathrm{~kg} / \mathrm{ha}$ do formulado 4-30-10 (10 kg/ha de $\mathrm{N}, 75 \mathrm{~kg} / \mathrm{ha}$ de $\mathrm{P}_{2} \mathrm{O}_{5}$ e $25 \mathrm{~kg} / \mathrm{ha}$ de $\mathrm{K}_{2} \mathrm{O}$ ). Para estudo do manejo da aveia com nitrogênio, utilizou-se nitrogênio (200 kg/ha) na forma de ureia, em três aplicações, cada uma com 66,6 kg/ha: a primeira no dia 28/6/2006, a segunda 31/7/2006 e a terceira no dia 28/8/2006.

O método de pastejo foi com lotação contínua e taxa de lotação variável. O pastejo foi realizado mantendo-se uma altura de pastagem de $15 \mathrm{~cm}$, com técnica de controle de altura com lotação variável (put and take) descrita por Mott \& Lucas (1952). O ajuste da altura de $15 \mathrm{~cm}$ era realizado através de medições com régua a cada 14 dias. Foram utilizados novilhos inteiros da raça Purunã de aproximadamente dez meses, com peso médio inicial de $200 \mathrm{~kg}$. A entrada dos animais foi no momento em que o perfil da pastagem atingiu $30 \mathrm{~cm}$ de altura média, momento que se deu aos 40 dias após a emergência das plantas. $\mathrm{O}$ período de pastejo totalizou 89 dias, divididos em três períodos experimentais. O início do pastejo deu-se no dia $12 / 7 / 2006$ e foi até $10 / 8 / 2006$ (primeiro período), o segundo período de 10/8/2006 até 8/9/2006 e o terceiro período de 8/9/2006 até 8/10/2006.

A massa de forragem foi avaliada no início do período experimental, por ocasião da entrada dos animais nos piquetes, e a cada 28 dias, através de 10 cortes por unidade experimental, em pontos aleatoriamente escolhidos com o uso de um quadro amostral de $0,25 \mathrm{~m}^{2}$. Da quantidade total de amostras, foram retiradas duas subamostras, uma para determinação da porcentagem de matéria seca e outra para separação manual e avaliação da composição botânica da pastagem e avaliação de seus componentes lâmina foliar, colmo e material morto.

Antes do início do pastejo foram alocadas duas gaiolas de exclusão ao pastejo por piquete (unidade experimental) para avaliação da taxa de acúmulo de matéria seca. As quantidades de matéria seca dentro e fora da gaiola foram obtidas por corte com tesoura, rente ao solo, numa área delimitada por um quadro de $0,25 \mathrm{~m}^{2}$. As amostras cortadas eram colocadas em saco de papel, secas em estufa de circulação de ar forçado à temperatura de $65^{\circ} \mathrm{C}$ durante quatro dias e posteriormente pesadas.

A taxa de acúmulo de matéria seca do período foi estimada por intermédio da equação descrita por Campbell (1966). A produção total de matéria seca foi calculada pelo somatório das produções dos períodos (taxa de acúmulo diário $\times$ número de dias do período) mais a massa de forragem inicial. A taxa de acúmulo diária de matéria seca (TAD) foi avaliada a cada 28 dias, aproximadamente empregando a técnica do triplo emparelhamento (Moraes et al., 1990).

Para avaliação dos componentes estruturais da pastagem (lâmina foliar, colmo, material morto) e da composição botânica da mesma, no caso do tratamento com a inclusão da leguminosa, na massa de forragem, foi feita separação manual de cinco amostras com o quadro de $0,25 \mathrm{~m}^{2}$ a cada 28 dias. Depois de separado botanicamente e por componentes, o material era colocado em sacos de papel, identificados e levados à estufa com circulação de ar forçado à temperatura de $65^{\circ} \mathrm{C}$, até atingirem peso constante quando, então, determinou-se a participação de cada componente na massa de forragem da pastagem. O percentual de cada gênero ou componente foi multiplicado pela massa de forragem do mesmo período para obtenção da massa de cada gênero ou componente em kg de MS/ha.

A capacidade de transporte (CA) por período, expressa em kg de peso vivo/ha/dia, foi calculada pela adição do peso médio dos animais testers (At) com o peso médio de cada animal regulador (Ar) multiplicado pelo número de dias que cada um permaneceu na pastagem (D) dividido pelo número de dias do período (NDP), conforme a fórmula:

$$
C A=A t+\frac{(A r 1 * D 1)}{N D P}+\frac{(A r 2 * D 2)}{N D P}+\frac{(A r n * D n)}{N D P}
$$

A taxa de lotação foi calculada pela divisão da capacidade de transporte pelo peso médio dos animaisteste.

O ganho médio diário e a capacidade de transporte média de todo o período experimental foram obtidos pela média ponderada dos pesos dos períodos, levando-se em consideração o número de dias de cada período.

O ganho médio diário dos animais (GMD) foi obtido pelas diferenças entre pesagens dos animais-teste, realizadas no início e no final de cada período experimental, e dividindo-se este valor pelo número de dias de cada período. Todas as pesagens foram precedidas de jejum de sólidos e líquidos de 12 horas.

A oferta real de forragem (OF) foi obtida pela razão entre a capacidade de transporte média do período e a disponibilidade diária de matéria seca para o mesmo período, multiplicando-se por 100. A disponibilidade diária de matéria seca de cada período foi obtida dividindo-se o valor de massa inicial de matéria seca de cada período acrescida da taxa de acúmulo diário de matéria seca do período.

Para a estimativa do desaparecimento de matéria seca utilizou-se a seguinte equação, descrita por Lupatini (1996): 


$$
D=\frac{P M S-(M F-M I)}{n^{\circ} \text { dias }}
$$

em que: $\mathrm{D}$ = desaparecimento de matéria seca em $\mathrm{kg} / \mathrm{ha} /$ dia; PMS = produção de matéria seca no período; $\mathrm{MF}=$ massa de forragem final do período (kg de MS/ha); MI = massa de forragem inicial do período ( $\mathrm{kg}$ de MS/ha).

Para o cálculo do desaparecimento em porcentagem de peso vivo, dividiu-se o valor absoluto de desaparecimento diário pela capacidade de transporte média do período e multiplicou-se por 100.

Determinou-se o rendimento por área, em termos de ganho de peso vivo por hectare (GPV) multiplicando-se o ganho médio diário médio dos animais-teste pela taxa de lotação (animal/ha) e pelo número de dias de pastejo.

Os resultados das avaliações foram submetidos à análise de variância. As variâncias foram avaliadas pelo teste Bartlett quanto à homogeneidade. As variáveis que se mostraram homogêneas tiveram os fatores em estudo avaliados pelo teste F. Quando os resultados revelaram significância ao nível de 5\% de probabilidade as médias foram comparadas pelo teste Tukey no nível de 5\% de probabilidade.

\section{Resultados e Discussão}

A massa de forragem inicial da pastagem, avaliada por ocasião do início do pastejo, que ocorreu aos 40 dias após a emergência das plantas, não foi influenciada pela adubação nem pela inclusão de trevo-branco, tendo uma produção de matéria seca média neste período inicial de $1.901 \mathrm{~kg} /$ ha de matéria seca. No manejo com adubação nitrogenada, a falta de influência do nitrogênio na massa de forragem aos 40 dias (16 dias após a aplicação do N) pode estar relacionada à decomposição da matéria orgânica, que nesta área é muito alta. Além disso, houve aplicação inicial de $10 \mathrm{~kg} / \mathrm{ha}$ de $\mathrm{N}$ na forma de adubação mineral de base adicionada na semeadura em todas as pastagens.

Dado semelhante foi observado por Assmann et al. (2004), que tampouco obteve resposta às doses de $\mathrm{N}$ na mistura de uma pastagem de aveia/azevém no início da avaliação, tendo uma média de $1.500 \mathrm{~kg} / \mathrm{ha}$ de matéria seca.

A data de entrada dos animais na pastagem define, em parte, a magnitude do vazio forrageiro de outono, no sistema de produção de integração lavoura-pecuária comum no sul do Brasil. A semelhança entre as pastagens na primeira avaliação de massa de forragem, que representa a própria produção de forragem no período de perfilhamento, pode indicar que este manejo de adubação nitrogenada não ajuda a antecipar a entrada dos animais nem a reduzir o vazio forrageiro de outono.
Não se observou interação significativa entre os períodos de avaliação nem entre os fatores em estudo para a massa de forragem.

A massa de forragem média no manejo com adição de $\mathrm{N}$ foi em média 28,3\% superior aos manejos com trevo e controle (Figura 1). A massa de forragem dependeu essencialmente da capacidade de transporte e não da adubação ou da inclusão de trevo-branco. Ressalta-se que o critério de manejo da pastagem adotado neste ensaio foi altura, adotando-se um valor preconizado de $15 \mathrm{~cm}$. A diferença significativa na massa de forragem está relacionada à densidade de forragem causada pela inclusão de trevo-branco ou pela adubação, uma vez que a altura não diferiu entre as parcelas nem entre os períodos $(\mathrm{P}>0,05)$.

A massa de forragem dos três períodos, independentemente da inclusão de trevo-branco ou da adubação nitrogenada, foi de 2.806,11 kg/ha. Esta quantidade de matéria seca produzida e mantida em método de lotação contínua de pastejo é considerada acima da recomendada por Assmann et al. (2003), em sistemas de integração lavoura-pecuária - que em solo argiloso deve ser em torno de $2.000 \mathrm{~kg} / \mathrm{ha}$-, para semeadura da cultura de verão. Neste experimento, o resultado obtido está próximo ao recomendado por Cassol (2003), de 3.000 kg/ha de matéria seca para a semeadura direta, em sistema de integração lavoura-pecuária para que não haja influência do pisoteio animal, podendo refletir na produtividade da cultura de verão.

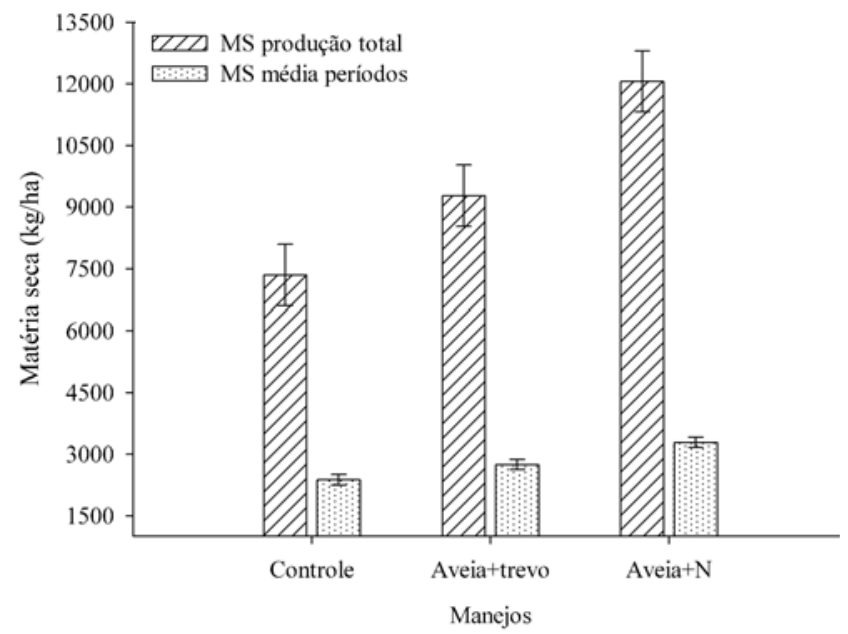

Barras coincidentes não apresentam diferença estatística significativa a 5\% pelo teste Tukey.

Figura 1 - Produção de massa de forragem total e média dos períodos em pastgem de azevém manejada com trevobranco ou leguminosa. 
A taxa de acúmulo diário de matéria seca não foi influenciada nem pelos períodos de avaliação nem pelo manejo, apresentando-se, em média, para os três períodos de avaliação, em torno de 70,45 kg de MS/ha/dia. Resultados semelhantes de taxa de acúmulo diário de matéria seca, em sistema de integração lavoura pecuária com doses de $\mathrm{N}$ em uma pastagem de aveia/azevém/trevo foram observados por Assmann et al. (2004), que encontraram uma taxa de acúmulo diário de matéria seca mínima e máxima durante todo o período de pastejo de 32,8 e 57,6 kg/ha de matéria seca para 0 e $300 \mathrm{~kg} / \mathrm{ha}$ de $\mathrm{N}$, respectivamente. Outros autores também observaram uma taxa de acúmulo diário de matéria seca semelhante às encontradas neste experimento, Lupatini et al. (1998) verificaram taxa de acúmulo diário de matéria seca de 96 kg de MS/ha em uma mistura de aveia e azevém sob uma dose de $300 \mathrm{~kg} / \mathrm{ha}$ de N. Na depressão central do Rio Grande do Sul foram verificadas, em pastagem de aveia e azevém, taxas de acúmulo diário de forragem entre 40 e $50 \mathrm{~kg} / \mathrm{ha}$ em experimentos com novilhas de corte sob pastejo com lotação contínua (Soares \& Restle, 2002; Roso et al., 2000; Frizzo et al., 2003; Freitas et al., 2002; Rocha et al., 2003).

Observou-se influência dos manejos sobre a produção total de matéria seca (Figura 1). A diferença entre o manejo do trevo e a pastagem controle pode ser atribuída à presença de trevos como provedores de nitrogênio para o sistema solo-planta-animal, fazendo com que a produção da pastagem fosse aumentada, porém foi ainda inferior à obtida com adição de $\mathrm{N}$, indicando que, no primeiro ano de implantação da pastagem consorciada, a inclusão da leguminosa não é suficiente em substituir a adubação de 200 kg de N/ha, sendo necessários estudos mais prolongados para que se possa estabelecer se esta substituição poderia ocorrer nos anos seguintes ao ano de implantação da pastagem.

Com a inclusão do trevo, a porcentagem de trevo no terceiro período de avaliação foi de $10,50 \%$ na composição botânica da pastagem, enquanto que no primeiro e segundo períodos de avaliação havia sido de 0,31 e 3,28\%, respectivamente. Este aumento deve-se principalmente pela diminuição da competitividade da poácea - pelo fato de estar em final de ciclo, com menor altura, e pelo fato de que velocidade de estabelecimento das leguminosas é mais lenta que a das demais gramíneas.

Os valores de produção de matéria seca total observados neste trabalho, de $7.348 \mathrm{~kg} / \mathrm{ha}$ no controle, $9.275 \mathrm{~kg} / \mathrm{ha}$ na pastagem de aveia com trevo e de $12.058 \mathrm{~kg} / \mathrm{ha}$ com nitrogênio são superiores aos encontrados por Assmann et al. (2004), que foi de 4.296 e 6.504 kg/ha sem utilização de $\mathrm{N}$ e com $300 \mathrm{~kg} / \mathrm{ha}$ de $\mathrm{N}$, respectivamente.

A oferta de forragem comportou-se de forma estável durante todo o período experimental, entre manejos e entre períodos, sendo a oferta média constatada de $14,9 \mathrm{~kg}$ MS/100 kg de peso vivo. Essa oferta de forragem, levando em consideração o sistema de integração lavoura-pecuária, está acima do proposto por Moraes et al. (1990), que é $12 \mathrm{~kg}$ de MS/100 kg de PV/dia.

Não se constatou diferença estatística entre os fatores em estudo quanto ao desaparecimento de matéria seca. A massa média de desaparecimento foi de 5,18 kg de MS/100 kg de peso vivo por dia. Embora o desaparecimento de matéria seca inclua, além do consumo, perdas de matéria seca por pisoteio e senescência, que não foram avaliadas, pode ser um indicativo do nível de consumo dos animas em pastejo.

Constatou-se interação significativa de período e manejo sobre o componente estrutural folha, em kg de MS/ha. No primeiro período, as parcelas que receberam nitrogênio tiveram maior massa de lâminas na sua massa de forragem e nos dois períodos subsequentes não houve diferença entre os fatores em estudo (Figura 2a).

No primeiro período, o controle apresentou maior massa de lâminas que as parcelas cultivadas com trevo, o que poderia ser explicado por uma competição das plantas de trevo com as plantas de aveia, fazendo com que estas apresentassem menor proporção de lâminas, mesmo quando comparadas à controle, que não recebeu $\mathrm{N}$ e nem estava consorciada com a fabácea. Já para o terceiro período, não houve diferença estatística significativa na massa de lâminas foliares entre os fatores em estudo. A maior proporção de tecido foliar na dieta do animal em pastejo proporciona maior qualidade e aumento de consumo de matéria seca (Burns et al., 1991), o que seria positivo sob o desempenho individual dos animais. A massa de lâminas, neste trabalho, está em função de modificações na estrutura da pastagem de acordo com os fatores em estudo e de possíveis diferenças na massa de forragem que, por sua vez, depende da intensidade de pastejo imposta.

Não se constatou influência da interação entre manejo e período sobre a massa de colmo nem para massa de material morto $(\mathrm{P}>0,05)$. Os períodos de avaliação influenciaram a quantidade de colmo na massa de forragem, independentemente do manejo utilizado (Figura 2). A massa de colmo no terceiro período foi 73\% e 70\% inferior à do primeiro e segundo períodos, respectivamente. Esta diminuição na massa no terceiro período deve-se a uma forte geada ocorrida neste período de avaliação, fato que prejudicou o desenvolvimento da aveia, que teve alguns perfilhos queimados, entrando assim no componente "material morto" mas, ao mesmo tempo, induziu o desenvolvimento de novos perfilhos, aumentando a proporção de lâminas foliares (Figuras 2). Pelo aparecimento 
de novos perfilhos e morte de outros, além da diminuição de colmo houve um aumento de material morto e um incremento na relação lâmina/colmo no terceiro período de avaliação.

Da mesma forma, apenas os períodos de avaliação influenciaram a massa de material morto (Figura 2), de modo que a produção de material morto no segundo e terceiro períodos de avaliação foram 387 e $438 \%$ superiores à primeira avaliação. Como foi mencionando anteriormente, este aumento deveu-se à ocorrência de forte geada.

Quanto à porcentagem de material morto em relação à produção de massa de forragem, esta foi de 13, 49 e 73\%, para o primeiro, segundo e terceiro períodos respectivamente. Valores semelhantes foram constatados por Cassol (2003), com valores em torno de 77\% e 74\% para alturas de pastagem de 0,10 e 0,20 m aos 79 dias de pastejo.

Valores inferiores ao deste estudo foram obtidos por Roso et al. (1999), em pastagens de triticale, aveia-preta ou triticale + aveia-preta + azevém, com massa de forragem de $1.670 \mathrm{~kg}$ de MS/ha no final do ciclo. Esses autores obtiveram valores de 24, 36 e 30\% de material morto em relação à massa de forragem, devido à senescência das plantas de triticale e aveia, que se encontravam próximas à fase reprodutiva.
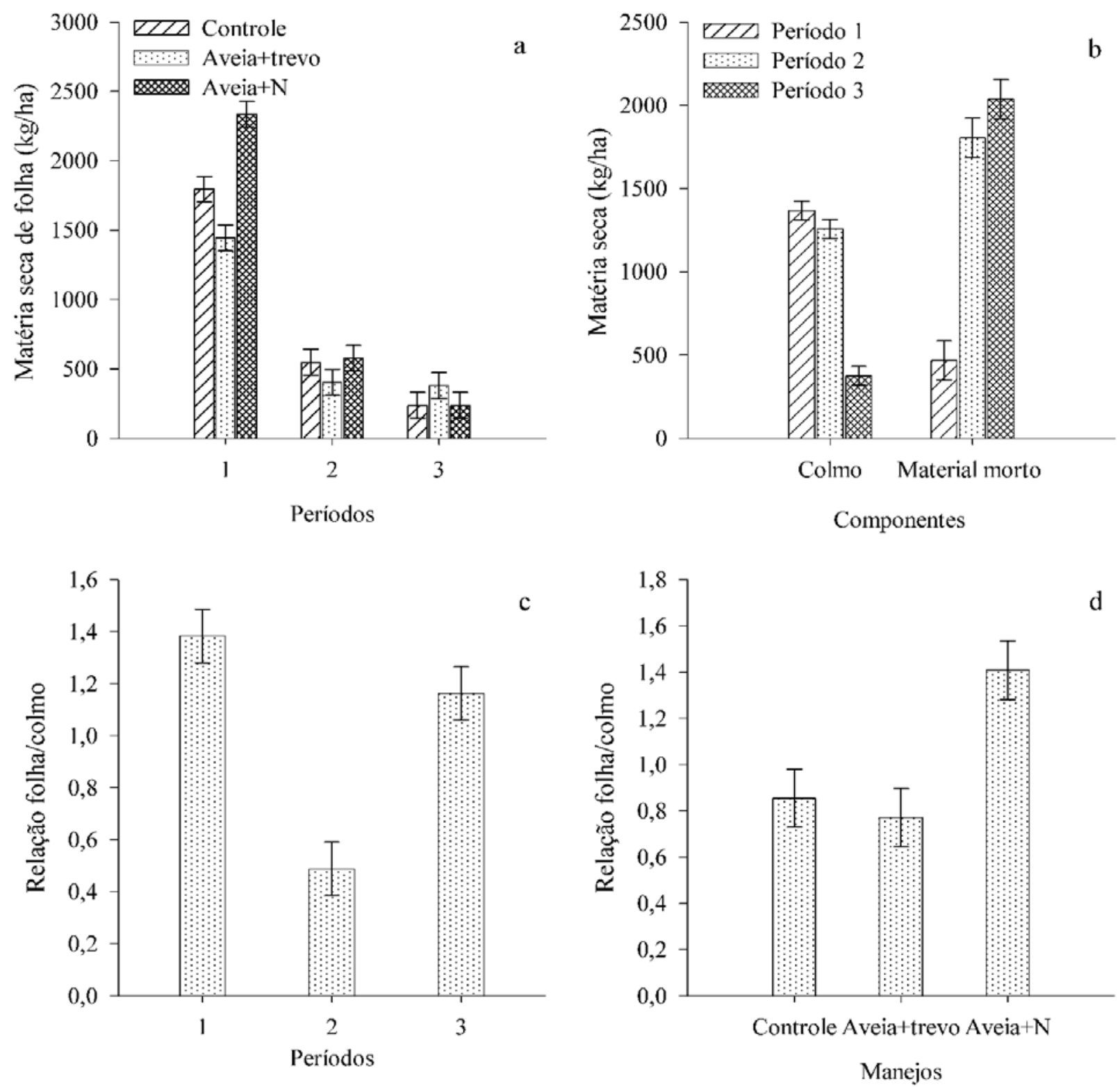

Barras coincidentes não apresentam diferença estatística significativa a 5\% pelo teste Tukey.

Figura 2 - Matéria seca de folha, massa de colmo e material morto e relação lâmina/colmo em pastagem de aveia em sistema de integração lavoura-pecuária. 
A relação lâmina/colmo foi inferior apenas no segundo período e foi recuperada no terceiro período, uma relação igual estatisticamente à observada no primeiro período (Figura 2). Esse resultado deveu-se provavelmente à geada ocorrida no final do período experimental, que induziu o aparecimento de novos perfilhos, aumentando a relação lâmina/colmo. Além da influência dos períodos sobre a relação lâmina/colmo, o tipo de manejo também influenciou a proporção lâmina/colmo, que foi melhor nas parcelas com aplicação de nitrogênio (Figura 2), cuja porcentagem de folhas foi 65 e $83 \%$ superior à obtida com a inclusão de trevo e do controle, respectivamente.

A relação lâmina/colmo das parcelas cultivadas com o consórcio aveia + trevo igualou-se às parcelas controle. Segundo Corsi \& Nussio (1992), o uso de adubação nitrogenada aumenta a densidade da pastagem e a produção de folhas no perfil da pastagem. De acordo com Mazzanti et al. (1994), o nitrogênio tem efeito pronunciado sobre o aparecimento e elongação de folhas nas poáceas.
O período e manejo da pastagem tiveram efeito sobre a capacidade de transporte, embora não tenha havido interação entre eles. A capacidade de transporte, independentemente do manejo aplicado, foi maior nos fatores em estudo que em alguma forma utilizava nitrogênio (Figura 3), principalmente na forma de adubação mineral, demonstrando a necessidade das poáceas de adequado provimento de nitrogênio. A capacidade de transporte foi maior com adição de $\mathrm{N}$, uma vez que a produção foi $17 \%$ e $28 \%$ superior em relação à encontrada com a inclusão do trevo e à pastagem controle, respectivamente.

A menor capacidade de transporte foi observada no manejo controle, que apresentou uma produção $10 \%$ inferior à observada no tratamento com inclusão da fabácea, mostrando desta forma que é indispensável a adubação nitrogenada, seja esta realizada via fertilizante ou via fixação simbiótica das fabáceas, nos sistemas de produção de carne.

Neste ensaio, as diferenças na produção de forragem (Figura 1) tiveram o mesmo comportamento das diferenças
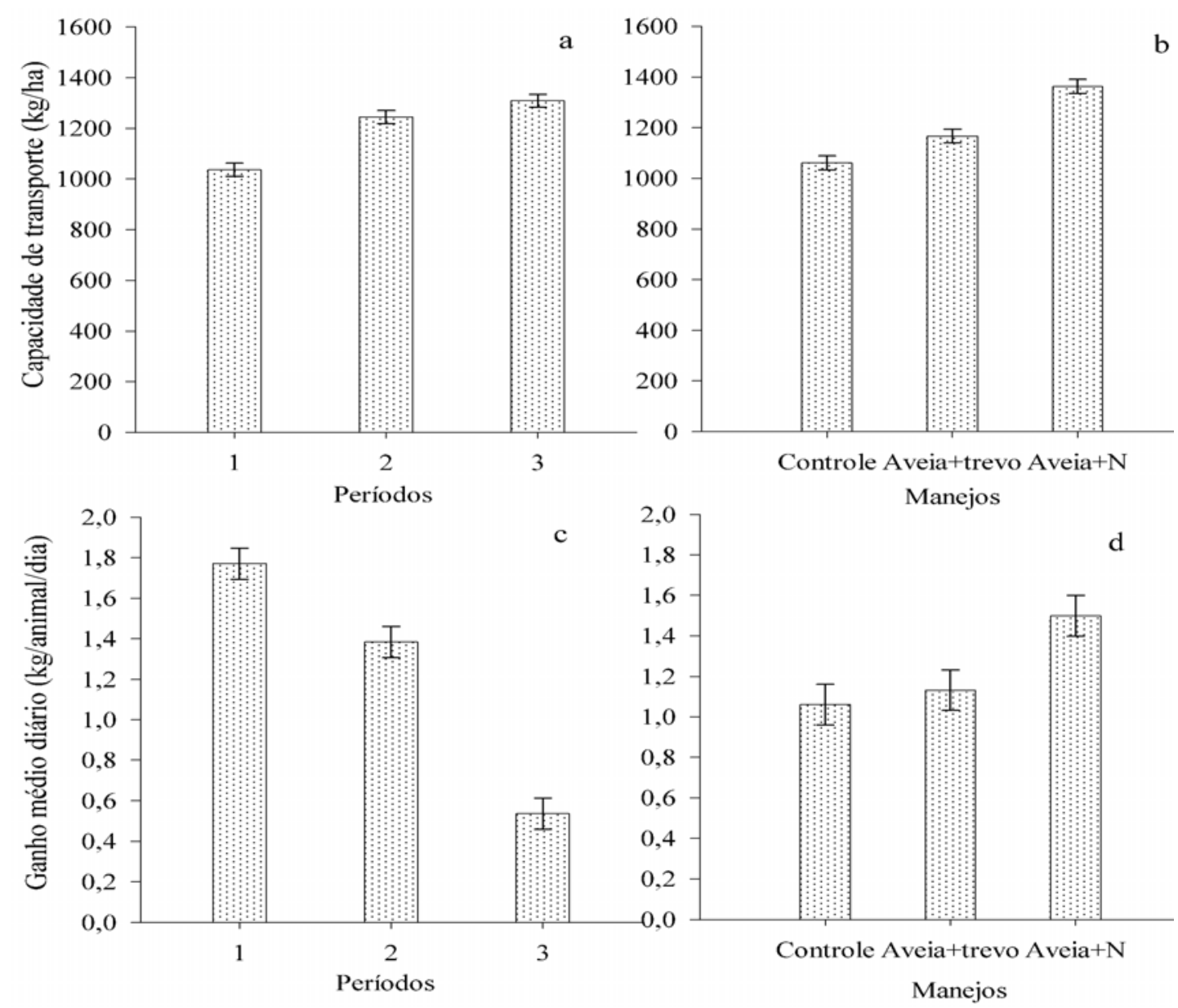

Barras coincidentes não apresentam diferença estatística significativa a 5\% pelo teste Tukey.

Figura 3 - Capacidade de transporte em pastagem de aveia em sistema de integração lavoura-pecuária. 
em termos de capacidade de transporte (Figura 3). Os valores encontrados confirmam as observações de outros trabalhos de que a adubação nitrogenada em gramíneas normalmente aumenta a capacidade de transporte suportada pela pastagem (Moojen, 1993; Gomide, 1994).

A capacidade de transporte foi maior no segundo e terceiro períodos que não diferiram estatisticamente entre si (Figura 3), sendo que a menor capacidade de transporte foi observada no primeiro período, que foi 20 e $26 \%$ inferior em relação ao segundo e terceiro períodos de pastejo, respectivamente.

Os valores encontrados de capacidade de transporte ao final do período de pastejo foram semelhantes aos obtidos por Restle et al. (1999) e Roso \& Restle (2000) e inferiores aos obtidos por Assmann et al. (2004) e Lesama \& Moojen (1999). A manutenção da capacidade de transporte do segundo para o terceiro períodos, meados de agosto a meados de outubro, foi obtida com cultivares de ciclo longo de aveia-preta e branca. Caso contrário, poderia se esperar redução da capacidade de suporte da pastagem.

Quanto ao ganho médio diário, foi verificado efeito estatístico significativo do manejo (Figura 3) e dos períodos. O ganho médio diário dos diferentes períodos foi de 1,77 ; 1,38; 0,54 kg/animal/dia para o primeiro, segundo e terceiro períodos de avaliação, respectivamente. O declínio no ganho médio diário no decorrer dos períodos acompanha a menor massa de lâminas foliares e o aumento da massa de material morto na massa de forragem. Significa que mudanças estruturais da pastagem diminuíram a qualidade da mesma e consequentemente o desempenho animal sobre ela.

O ganho médio diário do experimento foi de $1,23 \mathrm{~kg} /$ animal/dia, comprovando que a alta qualidade da forragem aproxima o animal de seu potencial de ganho animal médio. Ganhos menores foram encontrados por Quadros \& Maraschim (1987), Lesama \& Moojen (1999), Johson \& Morrison (1997), Laws et al. (2000) e Assmann et al. (2004) com ganho médio diário de 0,87; 0,96; 0,92; 0,92 e 0,95 kg/ animal/dia, respectivamente. Ganhos semelhantes foram obtidos por Lustosa (1998) e Cassol (2003) com ganho médio diário de 1,18 e 1,22 kg/animal/dia, respectivamente.

Como observado para a capacidade de transporte, o tipo de manejo influenciou o ganho médio diário, independentemente do período de avaliação. As parcelas que receberam nitrogênio (Figura 3), aplicado na forma de ureia, resultaram em maior ganho médio diário, que foi de $1,50 \mathrm{~kg} /$ animal/dia, enquanto para os manejos controle e pastagem consorciada resultaram em ganhos de 1,06 e $1,13 \mathrm{~kg} /$ animal/dia, respectivamente, ou seja, 32\% e 41\% superior ao manejo com trevo-branco e controle, respectivamente, evidenciando novamente a importância da adubação nitrogenada para pastagem. Resultados semelhantes com uso de adubação nitrogenada com bovinos de corte também foram observados por Lesama \& Moojen (1999) e Assmann et al. (2004).

Um dos principais benefícios da inclusão de leguminosas em pastagens de gramíneas de estação fria é devido ao fato de que elas melhoram o valor da dieta dos animais em pastejo (Poppi \& Mc Lennan, 1995), resultando em maior consumo pela maior velocidade de passagem no rúmen (Clark \& Ulyatt, 1984); ou também devido ao melhor aproveitamento pelos microrganismos do rúmen da proteína proveniente dos trevos em relação às gramíneas, pois a fermentação destes aumentaria a quantidade de proteína que entra no duodeno, aumentando a absorção de aminoácidos pelo animal (Beever et al., 1980).

Além disso, como o trevo-branco é uma leguminosa prostrada, o trevo-vermelho, uma leguminosa ereta, ambos mesclados a uma gramínea ereta (aveia), faria com que a distribuição vertical no perfil da pastagem fosse homogeneizada, uniformizando a densidade de forragem no dossel, favorecendo o pastejo (Carvalho et al. 2001).

A despeito das indicações de literatura apontar para maior ganho médio diário em pastagens que tenham leguminosas na sua composição, neste ensaio isso não aconteceu, o que pode ser explicado por três fatores principais: a proporção de leguminosas no terceiro período experimental foi de $10,5 \%$, ainda muito baixa para evidenciar os benefícios da leguminosa, não sendo efetiva no aumento de nitrogênio no sistema solo-planta-animal nem no aumento da digestibilidade da ingesta, que melhoraria o desempenho individual dos animais, como poderia ser esperado com a inclusão de trevos na mistura forrageira. Fortalecendo essa hipótese, Boller \& Nösberger (1987) sugerem uma proporção de trevo na mistura forrageira de pelo menos 50\%, para que haja uma maior fixação do $\mathrm{N}_{2} \mathrm{e}$, assim, maior aproveitamento do $\mathrm{N}$ pelas poáceas; pela maior massa de forragem no tratamento com adição de $\mathrm{N}$ mineral, na mesma altura de manejo, fazendo com que a densidade de forragem aumentasse no perfil da pastagem, favorecendo o consumo e; o maior ganho médio diário observado com aplicação de nitrogênio em relação ao controle provavelmente seja explicado pelo aumento do valor nutritivo da forragem, proteína bruta e digestibilidade in vitro da matéria orgânica (Soares \& Restle, 2002).

Os altos valores de ganho médio diário encontrados neste trabalho são justificados pela alta oferta de forragem disponibilizada aos animais, de 14,90 kg de MS/100 kg de peso vivo por dia, e pela alta taxa de desaparecimento, em média de 5,18 kg de MS/100 kg de peso vivo por dia.

Para o ganho de peso vivo por hectare, não foi observada interação $(\mathrm{P}>0,05)$ entre tratamento e período. Os períodos 
de avaliação influenciaram o ganho de peso vivo por hectare, cujas médias foram de 214; 163 e 65 kg PV/ha para o primeiro, segundo e terceiro período de avaliação, respectivamente (Figura 4). O menor ganho de peso vivo por hectare no terceiro período deveu-se à diminuição do ganho médio diário, ocasionada pela baixa qualidade da pastagem (Figura 2).

O manejo da pastagem influenciou o ganho de peso vivo por hectare total (Figura $4 \mathrm{~b}$ ). O ganho durante os 89 dias de pastejo foi de 541,49; 404,83 e 379,60 kg PV/ha para os fatores em estudo com adição de nitrogênio, com presença de trevo e controle respectivamente. Portanto, a adição de nitrogênio favoreceu o ganho de peso vivo por hectare de $25 \%$ em relação à inclusão de trevo e $30 \%$ maior que a controle. Resultados semelhantes foram observados por Assmann et al. (2004), que observaram ganho de peso vivo total por hectare $37 \%$ superior ao encontrado nesta pesquisa com aplicação de $300 \mathrm{~kg} / \mathrm{ha}$ de $\mathrm{N}$ em relação ao sem nitrogênio e por Moraes (1991), Lesama \& Moojen (1999) e Lustosa (1998), que também avaliaram pastagens de inverno usando adubação nitrogenada.

A exemplo do ganho médio diário, a produção animal total foi semelhante nos fatores em estudo controle e com inclusão de trevo e superior no tratamento com aplicação de nitrogênio. A produção animal total acompanha o comportamento da capacidade de transporte (esta acompanha as diferenças na produção de forragem) e do ganho médio diário, e as mesmas explicações dadas para as variáveis anteriores são usadas para explicar as diferenças de produção animal.

Admitindo que a presença de leguminosa aumente o ganho médio diário, pelas razões colocadas anteriormente, e que não influencia na produção de forragem quando a pastagem está bem suprida de N (Lesama \& Moojen, 1999), seria de se esperar que a produção animal fosse aumentada com a inclusão das leguminosas na pastagem. No entanto isto não ocorreu, pelas mesmas razões que o ganho médio diário não foi superior, inclusive inferior na pastagem com trevo em relação ao manejo com $\mathrm{N}$ químico.

Corroborando as hipóteses apontadas, Vipond et al.(1993) relatam que pastagens de trevos com gramíneas contendo não mais de $20 \%$ (neste ensaio foi de 10,5\%) de trevo, a produção animal total é semelhante a uma pastagem apenas de gramíneas que recebem de 150 a $180 \mathrm{~kg}$ de N/ha.

Um fator importante a ser considerado com relação ao trevo é que se trata de uma cultura dependente de tempo para se consolidar na área e os resultados obtidos neste experimento foram observados em uma pastagem onde o trevo era de primeiro ano. Desta forma, o cultivo do trevo não substitui a fertilização química e não contribuiu de forma significativa no provimento de $\mathrm{N}$ ao sistema soloplanta-animal e no aumento do valor nutritivo da dieta.
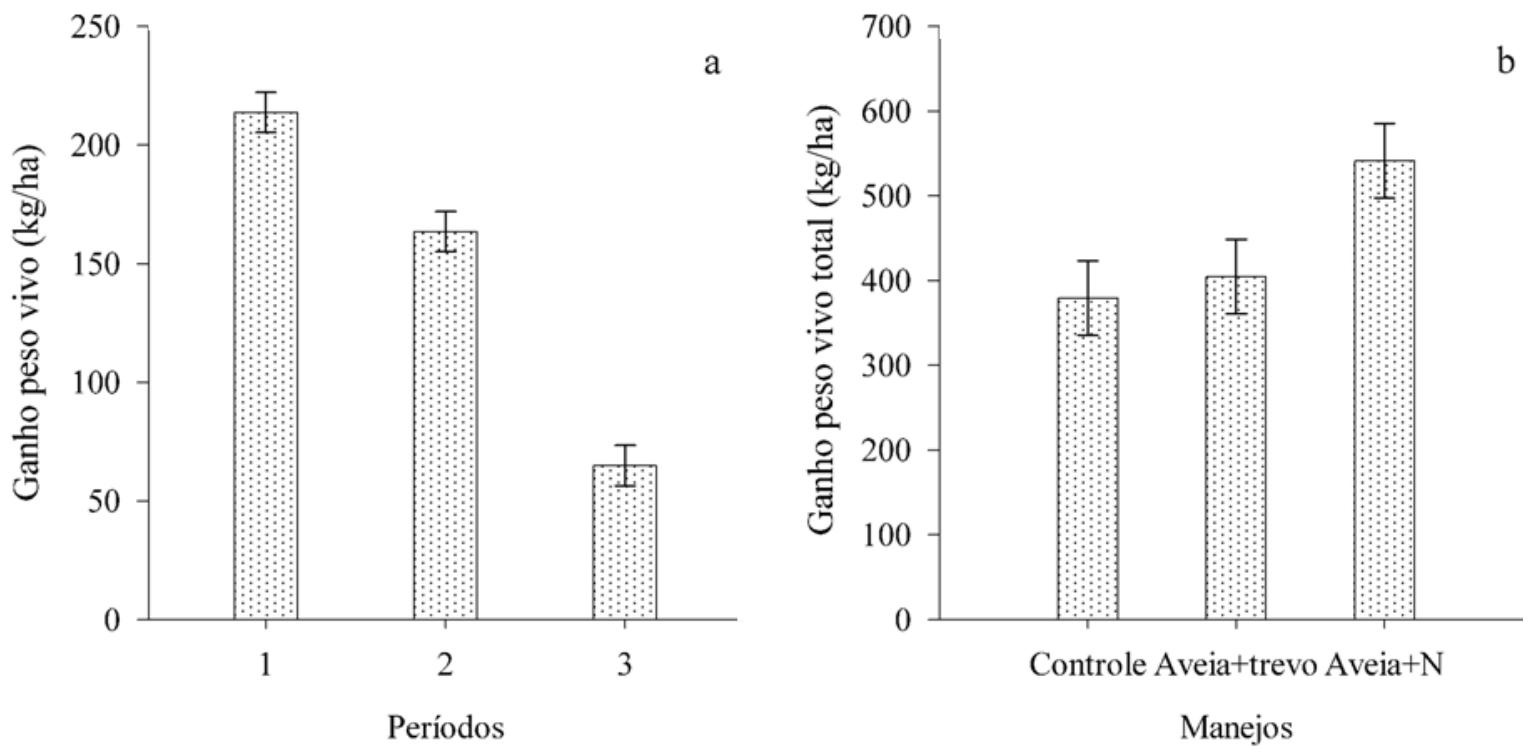

Barras coincidentes não apresentam diferença estatística significativa a 5\% pelo teste Tukey.

Figura 4 - Ganho de peso vivo total em pastagem de aveia em sistema de integração lavoura-pecuária. 


\section{Conclusões}

A inclusão de trevo-branco em consórcio com aveia no sistema de integração lavoura-pecuária não é suficiente para manter a sustentabilidade de sistemas intensivos de elevada produtividade. A produção de forragem e os parâmetros ligados à produção animal, como capacidade de transporte, ganho médio diário e produção de peso vivo por hectare, são assegurados somente pelo uso de nitrogênio via fertilização química. O não-atendimento da demanda de nitrogênio pode levar, a médio e longo prazo, à degradação do solo e do sistema.

\section{Referências}

ASSMANN, A.L.; PELISSARI, A.; MORAES, A. et al. Produção de gado de corte e acúmulo de matéria seca em sistema de integração lavoura-pecuária em presença e ausência de trevo-branco e nitrogênio. Revista Brasileira Zootecnia, v.33, n.1, p.37-44, 2004.

ASSMANN, T.S.; ASSMANN, A.L.; SOARES, A.B. et al. Fixação biológica de nitrogênio por plantas de trevo (Trifolium spp) em sistema de integração lavoura-pecuária no Sul do Brasil. Revista Brasileira Zootecnia, v.36, n.5, p.1435-1442, 2007.

ASSMANN, T.S.; RONZELLI JR., P.; MORAES, A. et al. Rendimento de milho em área de integração lavoura-pecuária sob o sistema plantio direto, em presença e ausência de trevobranco, pastejo e nitrogênio. Revista Brasileira de Ciência do Solo, v.27, n.4, p.675-683, 2003.

BEEVER, D.E.; ULYATT, M.J.; THOMSON, D.J. et al. The digestion of fresh perennial ryegrass (Lolium perenne cv. Melle) and white clover (Trifolium repens cv. Blanca) by growing cattle feds indoors. British Journal Nutricional, v.54, p.763, 1980.

BOLLER, B.C.; NÖSBERGER, J. Symbiotically fixed nitrogen from field-grown white and red clover mixed with ryegrasses at low levels of N15 fertilization. Plant and Soil, v.104, n.2, p.219-226, 1987.

BURNS, J.C.; POND, K.R.; FISHER, D.S. Effects of grass species on grazing steers: II. Dry matter intake and digesta kinetics. Journal of Animal Science, v.69, p.1199-1204, 1991.

CAMPBELL, A.G. Grazed pasture parameters. I. Pasture dry matter production and availability in a stocking rate and grazing manegement experiment with dairy cow. Journal of Agricultural Science, v.67, n.2, p.199-210, 1966.

CASSOL, L.C. Relação solo-planta-animal num sistema de integração lavoura-pecuária em semeadura direta com calcário na superfície. 2003. 143f. Tese (Doutorado em Agronomia - Ciência do solo) - Departamento de Solos da Universidade Federal do Rio Grande do Sul, Porto Alegre.

CARVALHO, P.C.F.; RIBEIRO FILHO, H.M.N.; POLI, C.H.C. et al. Importância da estrutura da pastagem na ingestão e seleção de dietas pelo animal em pastejo. In.: MATTOS, W.R.S. et al. (Ed.). Produção animal na visão dos brasileiros. Piracicaba: FEALQ, 2001. p.853-871.

CLARK, D.A.; ULYATT, M.J. Utilization of forage legumes in ruminant livestock production in New Zeland. In: BARNES, R.F.; BALL, P.R.; BROUHAM, R.W. et al. (Eds.) Forage legumes for energy efficient animal production. Palmersthon North, 1984. p.197-203.

CORSI, M.; NUSSIO, L.G. Manejo de capim elefante: correção e adubação do solo. In: SIMPÓSIO SOBRE MANEJO DA PAStAGEM, 10., 1992, Piracicaba. Anais... Piracicaba: Fundação de Estudos Agrários Luiz de Queiroz, 1992. p.87-117.
EMPRESA BRASILEIRA DE PESQUISA AGROPECUÁRIA EMBRAPA. Centro Nacional de Pesquisa de Solos. Sistema brasileiro de classificação de solos. Rio de Janeiro, 1999. 412p.

FREITAS, F.K.; ROCHA, M.G.; PILAU, A. et al. Dinâmica de uma pastagem de gramíneas temperadas sob duas disponibilidades de forragem. In: REUNIÃO ANUAL DA SOCIEDADE BRASILEIRA DE ZOOTECNIA, 39., 2002, Recife. Anais... Recife: Sociedade Brasileira de Zootecnia, 2002. (CD-ROM).

FRIZZO, A.; ROCHA, M.G.; RESTLE, J. et al. Produção de forragem e retorno econômico da pastagem de aveia e azevém sob pastejo com bezerras de corte submetidas a níveis de suplementação energética. Revista Brasileira de Zootecnia, v.32, n.3, p.632-642, 2003.

GOMIDE, J.A. Manejo de pastagens para produção de leite. In: SIMPÓSIO INTERNACIONAL DE FORRAGICULTURA, 1994, Maringá. Anais... Maringá: EDUEM, 1994. p.141-168.

JOHSON, R.H.; MORRISON, J. Effcts of spring fertilizer nitrogen and sward heijh on production from perennil ryegrass/white clover swards grazed by beef cattle. Grass and Forage Science, v.52, p.322-324, 1997.

LAWS, J.A.; PAIN, B.F.; JARVIS, S.C. et al. Comparison of grassland systems for beef catle using self-contained farmlets: effects of contrasting nitrogen inputs and management strategies on nitrogen budgets, and herbage and animal production. Agriculture Ecosystems and Environment, v.80, p.243-254, 2000.

LESAMA, M.F.; MOOJEN, E.L. Produção animal em gramíneas de estação fria com fertilização nitrogenada ou associadas com leguminosa, com ou sem fertilização nitrogenada. Ciência Rural, v.29, n.1, p.123-128, 1999.

LUPATINi, G.C. Produção animal em milheto (Pennisetum americanum (L.) Leeke) submetido a níveis de adubação nitrogenada. 1996. 126f. Dissertação (Mestrado em Zootecnia) - Universidade Federal de Santa Maria, Santa Maria.

LUPATINI, G.C.; RESTLE, J.; CERETA, M. et al. Avaliação da mistura de aveia-preta e azevém sob pastejo submetida a níveis de nitrogênio. Pesquisa Agropecuária Brasileira, v.33, n.11, p.1939-1943, 1998.

LUSTOSA, S.B.C. Efeito do pastejo nas propriedades químicas do solo e no rendimento de soja e milho em rotação com pastagem consorciada de inverno no sistema plantio direto. 1998. 84f. Dissertação (Mestrado em Agronomia - Ciência do Solo) - Universidade Federal do Paraná, Curitiba.

MAZZANTI, A.; LEMAIRE, G.; GASTAL, F. The effect of nitrogen fertilization upon herbage production of tall fescue sward continuously grazed with sheep. 1. Herbage growth dynamics. Grass and Forage Science, v.49, n.2, p.111-120, 1994.

MOOJEN, E.L. Avaliação de milheto (Pennisetum americanum (L.) Leeke) sob pastejo e níveis de adubação nitrogenada. 1993. 39f. Tese (Progressão a Professor Titular) - Universidade Federal de Santa Maria, Santa Maria.

MORAES, A. Produtividade animal e dinâmica de uma pastagem de pangola (Digitaria decumbens Stent), azevém (Lolium multiflorum Lam.) e trevo-branco (Trifolium repens L.), submetida a diferentes pressões de pastejo. 1991. $200 \mathrm{f}$. Tese (Doutorado em Agronomia - Zootecnia) - Faculdade de Agronomia da Universidade Federal do Rio Grande do Sul, Porto Alegre.

MORAES, A.; MOOJEN, E.L.; MARASCHIM, G. E. Comparação de métodos de taxas de crescimento em uma pastagem submetida a diferentes pressões de pastejo. In: REUNIÃO ANUAL DA SOCIEDADE BRASILEIRA DE ZOOTECNIA, 27., 1990, Campinas. Anais... Campinas: Sociedade Brasileira de Zootecnia, 1990. p.332.

MOTT, G.O.; LUCAS, H.L. The design conduct and interpretation of grazing trials on cultivated and improved pastures. In: INTERNATIONAL GRASSLAND CONGRESS, 6., 1952, Pennsylvania. Proceedings... Pennsylvania: State College Press, 1952. p.1380-1395. 
POPPI, D.P.; Mc LLENAN, S.R. Protein and energy utilization by ruminants at pasture. Journal of Animal Science, v.73, p.278-290, 1995.

QUADROS, F.L.F.; MARASCHIN, G.E. Desempenho animal em misturas de espécies forrageiras de estação fria. Pesquisa Agropecuária Brasileira, v.22, n.5, p.535-541, 1987.

RESTLE, J.; ROSO, C.; SOARES, A.B. Produção animal e retorno econômico em misturas de gramíneas anuais de estação fria. Revista Brasileira de Zootecnia, v.28, n.2, p.235-243, 1999.

ROCHA M.G.; RESTLE, J.; FRIZZO, A. et al. Alternativas de utilização da pastagem hibernal para recria de bezerras de corte. Revista Brasileira de Zootecnia, v.32, n.2, p.383-392, 2003. ROSO, C.; RESTLE, J.; SOARES, A.B. et al. Aveia-preta, triticale e centeio em mistura com azevém. 1- Dinâmica produção e qualidade de forragem. Revista Brasileira de Zootecnia, v.29, n.1, p.75-84, 2000.
ROSO, C.; RESTLE, J.; SOARES, A.B. et al. Produção e qualidade de forragem da mistura de gramíneas anuais de estação fria sob pastejo contínuo. Revista Brasileira de Zootecnia, v.28, n.3, p.459-467, 1999.

ROSO, C.; RESTLE, J. Aveia-preta, triticale e centeio em mistura com azevém. 2. Produtividade animal e retorno econômico. Revista Brasileira de Zootecnia, v.29, n.1, p.85-93, 2000.

SOARES, A.B.; RESTLE, J. Adubação nitrogenada em pastagem de triticale mais azevém sob pastejo com lotação contínua: recuperação de nitrogênio e eficiência na produção de forragem. Revista Brasileira de Zootecnia, v.31, n.1, p.43-51, 2002.

VIPOND, J.E.; SWIFT, G.; NOBLE, R.C. et al. Effects of clover in the diet of grazed lambs on production and carcass composition. Animal Production v.57, p.253-261, 1993.

WHITEHEAD, D.C. Grassland nitrogen. Wallingford: CAB International, 1995. 397p. 